\title{
PARAMETRIZAÇÕES DE CAMADA LIMITE E TEMPERATURAS MÍNIMAS EM UM MODELO NUMÉRICO DE MESOESCALA
}

\author{
Adriano Battisti ${ }^{1}$, Felipe Denardin Costa $^{2}$, Gervásio Annes Degrazia ${ }^{1}$, Otávio Costa \\ Acevedo $^{1}$, Daniel C. Santos ${ }^{1}$, Erikson M. G. de Oliveira ${ }^{1}$, Pablo E. S. Oliveira ${ }^{1}$, Viviane da \\ S. Guerra ${ }^{1}$ \\ ${ }^{1}$ Universidade Federal de Santa Maria - UFSM \\ Universidade Federal do Pampa - UNIPAMPA \\ adrianotbattisti@gmail.com
}

\section{RESUMO}

A relação da temperatura mínima com a parametrização de camada limite atmosférica foi estudada. Além disso, o erro da previsão foi associado às características do relevo do modelo WRF. De forma geral, os resultados mostraram que o modelo superestima as temperaturas na maioria das estações estudadas, sendo de forma mais intensa nas parametrizações que produziram mais mistura.

\begin{abstract}
The relation between the minimum temperature and the parameterization of the planetary boundary layer was studied. Furthermore, the forecast error is associated with features of relief of the WRF model. Overall, the results show that the model overestimates temperatures in most of the stations studied, and more intense in parameterizations which produce much mixture.
\end{abstract}

\section{INTRODUÇÃO}

A temperatura mínima está intimamente ligada à camada limite estável (CLE). Os processos que ali ocorrem precisam ser bem representados numa parametrização de camada limite atmosférica (CLA) para uma boa previsão.

Os experimentos com modelagem de coluna única feitos pelo Global Energy and Water Cycle Experiment (GEWEX) Atmospheric Boundary-Layer Study (GABLS) mostram que tanto para a $1^{\mathrm{a}}$ (CUXART et al., 2006) como para a $2^{\mathrm{a}}$ intercomparação de modelos (SVENSSON; HOLTSLAG, 2006) feitas por este projeto europeu na parte de CLA, existe significativa variabilidade nos perfis de temperatura e de velocidade do vento. E esta variabilidade estaria associada às diferentes parametrizações usadas.

Neste sentido, analisam-se simulações feitas pelo modelo de mesoescala Weather Research and Forecast System (WRF) utilizando-se diferentes parametrizações de CLA. O objetivo é mostrar o erro da temperatura mínima prevista por cada esquema, associando este erro com o perfil de CLE reproduzido e com características topográficas. 


\section{MATERIAL E MÉTODOS}

Utilizou-se o modelo atmosférico de mesoescala WRF, fazendo-se simulações com duas grades aninhadas, uma de 48 e outra de $12 \mathrm{~km}$ de resolução horizontal, centradas no RS. Os dias estudados foram 26 e 31 de Julho de 2012, com céu claro no RS, apenas encoberto nas áreas mais próximas à Santa Catarina (SC) no dia 26. As condições de contorno utilizadas são as previsões feitas pelo modelo global Global Forecasting System (GFS) para os dias estudados (NCDC - NOAA, 2013).

Quatro diferentes parametrizações de CLA foram estudadas: Yonsei University (YSU) Planetary Boundary Layer (PBL); Mellor-Yamada-Janjic (MYJ) PBL; Quasi-Normal Scale Elimination (QNSE) PBL; UW PBL.

Para fazer a comparação utilizaram-se 26 estações do Instituto Nacional de Meteorologia (INMET) no estado do RS.

\section{RESULTADOS E DISCUSSÃO}

$\mathrm{Na}$ figura 1, apresenta-se um exemplo da diferença de perfis de temperatura potencial e temperatura à 2 metros ( $\mathrm{t} 2 \mathrm{~m})$ entre a noite com vento fraco (1a) e com vento mais forte (1b). Percebe-se claramente que na noite com vento de magnitude maior, houve mais mistura próxima da superfície em comparação com a noite de vento fraco. Além disso, a parametrização YSU produziu mais mistura do que as outras na noite com mais vento.

a)

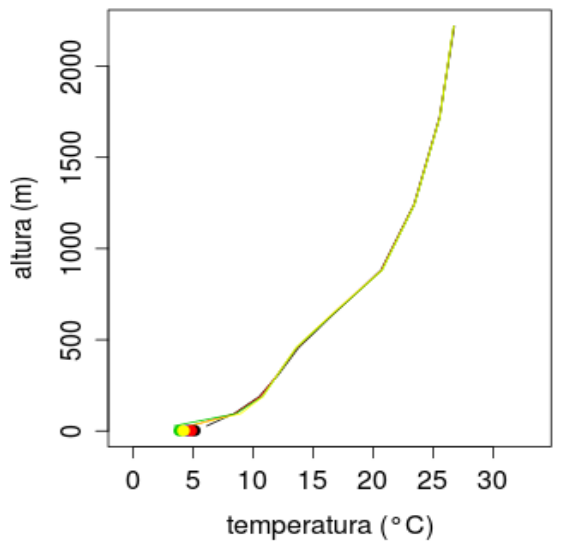

b)

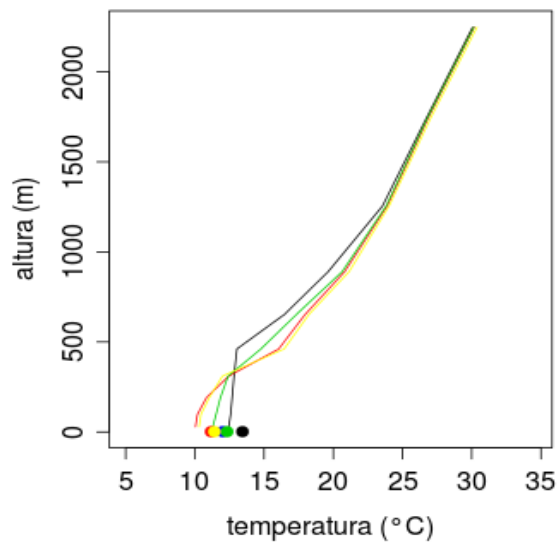

Figura 1 - Perfil de temperatura potencial e t2m para a estação de São Borja em a) uma noite de vento fraco, mais estável; e em b) uma noite de vento mais forte. Sendo preto: YSU; vermelho: MYJ; verde: QNSE; amarelo: UW; azul: INMET.

A figura 2 mostra o erro da previsão em função da diferença de altitudes da estação e do ponto de grade mais próximo. Percebe-se uma forte dependência do erro da previsão com a dificuldade do modelo em representar o relevo na noite mais estável. Quanto mais alto o modelo situa a estação em relação onde ela realmente se encontra, mais quente ela fica na simulação. Isso pode ser explicado pelo fato de o modelo representa uma altura média da região, sendo que quando a estação estiver abaixo dessa média, tende a ficar mais estável e com menor temperatura. Já para a noite com mais vento essa dependência não acontece, pois a conexão é maior. 

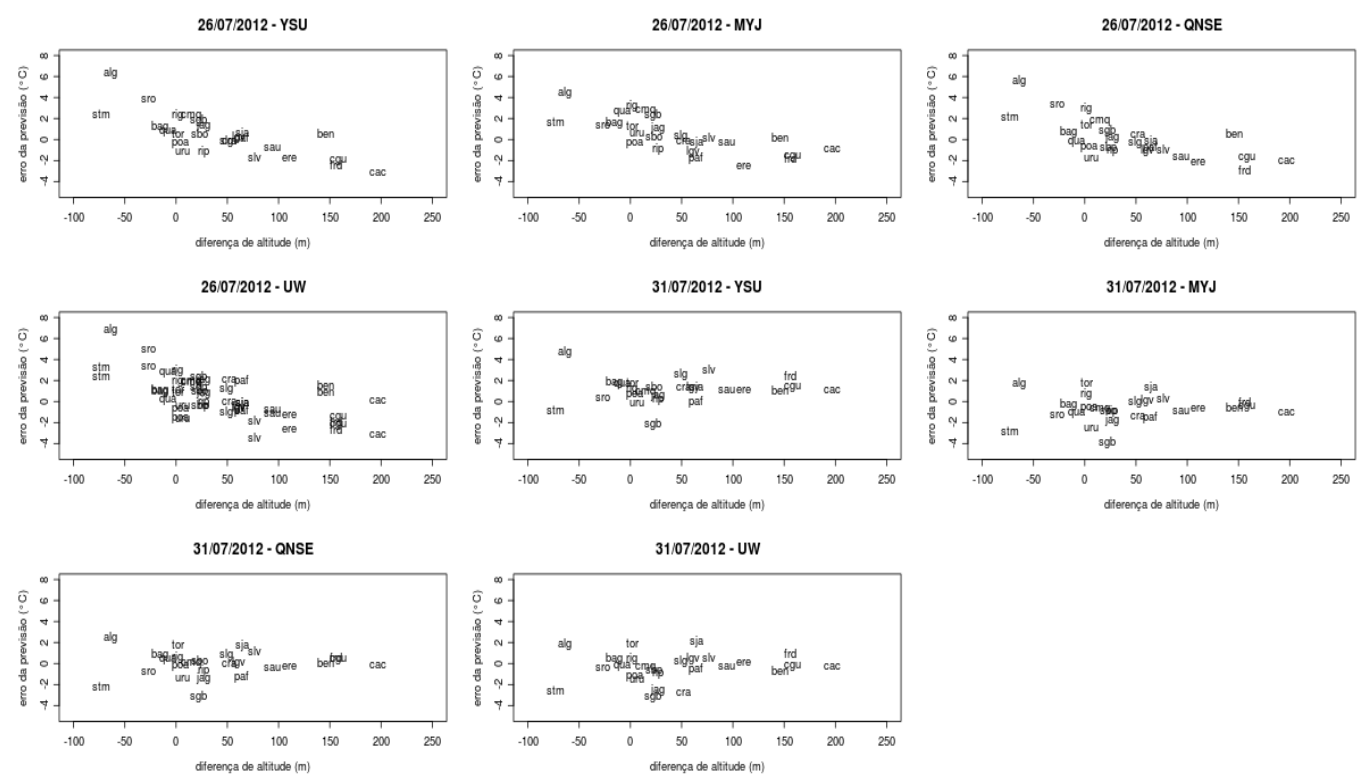

Figura 2 - Erro da previsão (prevista - registrada) em função da diferença das altitudes da estação e do modelo.

\section{CONCLUSÕES}

Houve claras diferenças entre os resultados da noite com pouco vento e com mais vento. Uma delas é o fato de o modelo ter reproduzido a maior mistura esperada na noite com vento mais intenso, apesar de que em alguns esquemas, esta reprodução foi maior que outros. Isso levou a maiores distinções entre as parametrizações na $t 2 \mathrm{~m}$ prevista. Outra diferença é a dependência do erro da previsão com o desvio de alturas, real e do modelo, para a noite de pouco vento, em todos os esquemas; o que não acontece para a outra noite.

Portanto, esses dois motivos evidenciam a dificuldade ainda existente de um modelo numérico de mesoescala em reproduzir importantes processos da CLE.

\section{AGRADECIMENTOS}

Ao Programa de Pós-Graduação de Meteorologia da UFSM e à Coordenação de Aperfeiçoamento de Pessoal de Nível Superior (CAPES) pela bolsa de estudo e ao NCDCNOAA e INMET pelos dados necessários para este trabalho.

\section{REFERÊNCIAS BIBLIOGRÁFICAS}

CUXART, J. et al. Single-column model intercomparison for a stably stratified atmospheric boundary layer. Boundary-Layer Meteorology, v. 118, p. 273-303, 2006.

SVENSSON, G.; HOLTSLAG, A. A. M. Single column modeling of the diurnal cycle based on CASES99 data - GABLS second intercomparison project. In: 17TH SYMPOSIUM ON BOUNDARY LAYERS AND TURBULENCE, San Diego, USA. Anais... Boston, USA: American Meteorological Society, 2006. 